\title{
Article \\ Separation of Lignocellulose and Preparation of Xylose from Miscanthus lutarioriparius with a Formic Acid Method
}

\author{
Jia Ouyang ${ }^{1,+} \oplus$, Wen-Qiang He ${ }^{1,+}$, Qing-Ming $\mathrm{Li}^{1}{ }^{1}$, Liang Chen ${ }^{2}$, Xiao-Fen $\mathrm{Wu}^{2, *}$ and Xiao-Jun $\mathrm{Su}^{1,3, *}$ \\ 1 College of Food Science and Technology, Hunan Agricultural University, Changsha 410128, China; \\ absinthe7@126.com (J.O.); cockroachzhifubao@163.com (W.-Q.H.); lqm@hunau.edu.cn (Q.-M.L.) \\ 2 Institute of Nuclear Agricultural Science and Space Breeding, Hunan Academy of Agriculture Sciences, \\ Changsha 410125, China; chenliang@hunaas.cn \\ 3 Hunan Engineering Laboratory for Alcohol Fuels from Biomass, Changsha 410128, China \\ * Correspondence: wuxiaofen@hunaas.cn (X.-F.W.); sxj@hunau.edu.cn (X.-J.S.); \\ Tel.: +86-731-8469-1562 (X.-F.W.); +86-731-8467-3522 (X.-J.S.) \\ + These authors contributed equally to this work.
}

Citation: Ouyang, J.; He, W.-Q.; Li, Q.-M.; Chen, L.; Wu, X.-F.; Su, X.-J. Separation of Lignocellulose and Preparation of Xylose from Miscanthus lutarioriparius with a Formic Acid Method. Appl. Sci. 2022, 12, 1432. https://doi.org/10.3390/ app12031432

Academic Editor: Luca Fiori

Received: 31 December 2021

Accepted: 25 January 2022

Published: 28 January 2022

Publisher's Note: MDPI stays neutral with regard to jurisdictional claims in published maps and institutional affiliations.

Copyright: (C) 2022 by the authors. Licensee MDPI, Basel, Switzerland. This article is an open access article distributed under the terms and conditions of the Creative Commons Attribution (CC BY) license (https:// creativecommons.org/licenses/by/ $4.0 /)$.

\begin{abstract}
Efficient component separation technology is one of the key ways to improve the efficiency of lignocellulose bioconversion. In this study, the formic acid method was used to separate the components of lignocellulose from Miscanthus lutarioriparius, hemicellulose was degraded into xylose simultaneously, and the composition and structure of the separated components were analyzed. Then, xylose was further purified with activated carbon for decolorization and resins for the removal of formic acid and other monosaccharide impurities. The results showed that formic acid could effectively separate the cellulose, hemicellulose, and lignin of lignocellulose with recoveries of $91.7 \%, 80.2 \%$, and $85.3 \%$, respectively. Structural analyses revealed that the cellulose and lignin underwent different degrees of formylation during the formic acid treatment, yet their primary structures remained intact, and the crystallinity of cellulose increased significantly. By GC-MS and HPLC analysis, xylose was the main component of hemicellulose extract, accounting for $74.90 \%$. The activated carbon treatment decolorized the xylose extract more than $93.66 \%$ and gave a xylose recovery of $88.58 \%$. D301 resin could effectively remove more than $99 \%$ of the formic acid residue in xylose. The xylose extract was further purified by removing arabinose and other monosaccharide impurities with Dowex 50wx4 resin, which increased the purity to $95 \%$. The results demonstrated that the formic acid method is an effective method to separate lignocellulose and prepare xylose, and it has broad application prospects in the field of bio-refining lignocellulose resources such as Miscanthus lutarioriparius
\end{abstract}

Keywords: Miscanthus lutarioriparius; formic acid method; fractionation; hemicellulose; xylose

\section{Introduction}

Lignocellulose is the most abundant renewable organic resource on earth, but it is not fully utilized. It can be degraded and converted into liquid fuels, bio-based materials, and various platform compounds by biorefinery for energy saving, consumption reduction, and emission reduction, which is considered an important strategic approach to solve urgent problems in resources, environment, rural development, and population health for sustainable development [1]. Lignocellulose is mainly composed of cellulose (30 45\%), hemicellulose (20 25\%), and lignin (15 25\%). Hemicellulose can be used to produce products such as xylose, furfural, xylitol, and xylo-oligosaccharides, and it can be further derived into biofuels, bio-based materials, and chemicals [2-4]. In nature, cellulose, hemicellulose, and lignin are combined with each other and closely linked to form complex supramolecular complexes, which makes lignocellulose difficult to effectively degrade and utilize; meanwhile, the enzymatic hydrolysis of cellulose largely depends on the adsorption of enzymes on the substrate, while lignin can irreversibly adsorb enzymes, leading to 
enzyme inactivation [5]. In order to realize the conversion of lignocellulosic resources to biomass energy, the separation of cellulose and hemicellulose from lignocellulose by efficient technology is key to improve the bioconversion efficiency.

Effective separation methods aim to change the supramolecular structure of the cellulose-hemicellulose-lignin matrix to loosen the highly ordered cellulose chains and thus subsequently convert the biomass into fermentable free monosaccharides efficiently under the action of enzymes, microorganisms, etc. [6]. Currently, commonly used separation methods include physical methods, acid methods, alkali methods, steam blasting methods, and ionic liquid methods [7-11]. All these methods can effectively increase the accessible surface area of cellulose and enzymes and promote the recovery of hemicellulose and lignin fractions, yet showing the disadvantages of equipment corrosion, serious environmental pollution, high energy consumption, and high cost. The organic solvent method is an emerging green separation method with mild treatment conditions and the advantage of easy solvent recovery. Formic acid, as a biomass-derived organic acid, has the advantages of being relatively nontoxic and having a low boiling point, low corrosiveness, low price, and high hydrogen bonding value, which can realize multiple recycling of the separation solvent and can effectively reduce the solvent consumption and production costs [12]. For the component separation of lignocellulose, formic acid can well dissolve lignin and break the $\beta-\mathrm{O}-4$ bond of lignin. Meanwhile, the hemicellulose is hydrolyzed into mono- and oligo-saccharides, while cellulose solids are separated well. Lignin can be precipitated with deionized water to eventually achieve the "one-step" separation of the three major components of lignocellulose $[13,14]$. Studies have shown that the formic acid method can effectively be applied to the component separations of corn cob [15], corn straw [16,17], wheat straw [18], Pterocarpus macarocarpus Kurz [19], bamboo [20,21], etc.

As a $C_{4}$ perennial herbaceous plant, Miscanthus lutarioriparius $(M L)$ belongs to the genus Miscanthus in the Poaceae family, which is endemic in China [22,23]. The ML straw contains a high amount of lignocellulose, and its content and quality of cellulose are better than those of the traditional fibrous plants such as Phragmites australis and Populus simonii, so it is a non-grain material with great potential for biomass energy production. The efficient and green separation of lignocellulose components will greatly promote the development of high-value utilization and bio-refining of lignocellulose. In this study, we used the formic acid method to separate lignocellulose components from $M L$ straw in the Dong-ting Lake area of China, and characterized the separated components. Then, activated carbon was used to decolorize xylose, which was the degradation product of hemicellulose, and then resin was used to separate and purify xylose after decolorization. This was to improve the purity of xylose and form a green and efficient new process technology for the production of xylose, in order to provide technical support for the high-value utilization of the whole biomass of $M L$.

\section{Materials and Methods}

\subsection{Material}

$M L$ straw was harvested from the Dong-ting Lake area in China, naturally dried, and sieved through 40 meshes, and the feedstock was stored at room temperature for the following experiments. Standards of xylose, arabinose, glucose, etc. were all purchased from Sigma Chemical Co. (St. Louis, MO, USA). Dowex 50wx4 ion-exchange resin was purchased from Thermo Fisher Technology Co., Ltd. (Waltham, MA, USA). Other resins, activated carbon, formic acid ( $\geq 88 \mathrm{wt} . \%)$, and other reagents were from Sinopharm Chemical Reagent Co., Ltd. (Shanghai, China). All reagents were of analytical grade unless otherwise stated. Purified water for experiments was produced from an Eco-S15 water system (Shanghai Hitech Instrument Co., Ltd., Shanghai, China).

\subsection{Formic Acid Pretreatment of Miscanthus lutarioriparius Straw}

$M L$ straw was treated by the same method of lignocellulosic fractionation adapted from Jin et al. [16] and schematized in Figure 1. An amount of $500 \mathrm{~g}$ of $M L$ straw was mixed 
with $88 \mathrm{wt} . \%$ formic acid at a material to liquid ratio of 1:10 $(\mathrm{m} / \mathrm{v})$ in an EX-10L glass reactor (Yaote Instrument Inc., Shanghai, China) and allowed to pretreat at $100{ }^{\circ} \mathrm{C}$ for $3 \mathrm{~h}$. The stirring rate was $280 \mathrm{r} / \mathrm{min}$. After the reaction, filtration was carried out to separate the solid residue (crude cellulose, labeled as $R_{1}$ ) and formic acid filtrate $\left(F_{1}\right) . R_{1}$ was washed with formic acid ( $5 \mathrm{~L}$ ) followed by deionized water to neutral and then dried at $60{ }^{\circ} \mathrm{C}$. $\mathrm{F}_{1}$ was evaporated at $50^{\circ} \mathrm{C}$ with $150 \mathrm{rpm}$ using a rotary evaporator (RE-2000B, Shanghai Yarong Biochemistry Instrument Factory, Shanghai, China) to recycle formic acid and collect concentrated liquor. Then, the concentrated liquor was collected for concentration, and deionized water was added to precipitate residue and wash to neutral. Then, it was dried at $60^{\circ} \mathrm{C}$ to afford crude lignin $\left(R_{2}\right)$, and the filtrate $\left(F_{2}\right)$ was soluble hemicellulose.

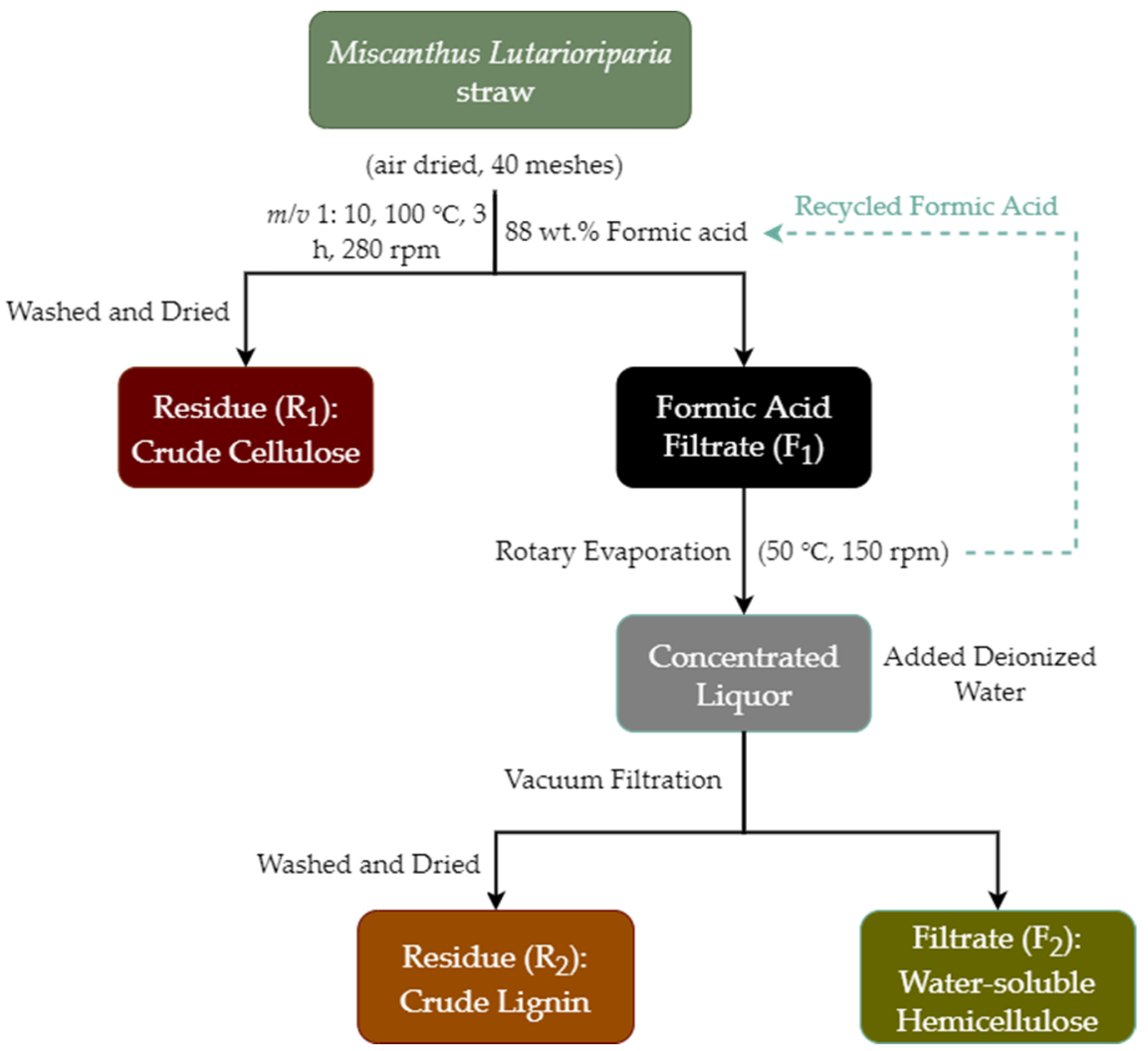

Figure 1. Schematic diagram of the experimental procedure of the formic acid method.

\subsection{Composition Analysis of Crude Cellulose and Lignin}

The chemical compositions analysis of $M L$ straw, separated crude cellulose, and crude lignin were measured by the National Renewable Energy Laboratory (NREL) standard analytical procedure (NREL/TP-510-42618, Standard two-step acid hydrolysis) [24]. Briefly, the sample $\left(300 \mathrm{mg}\right.$ ) was hydrolyzed with $3 \mathrm{~mL}$ of $72 \%(w / w)$ sulfuric acid at $30{ }^{\circ} \mathrm{C}$ for $60 \mathrm{~min}$. After hydrolysis, the obtained acid sample was diluted until a final sulfuric acid concentration of $4 \%(w / w)$ was obtained by adding distilled water $(84 \mathrm{~mL})$, and then it was allowed to react at $121^{\circ} \mathrm{C}$ for $60 \mathrm{~min}$ in a GI54DWS automatic pressure steam sterilizer (Zealway Instrument Inc., Xiamen, China).

The reaction mixture was filtrated, and the residue was dried at $105{ }^{\circ} \mathrm{C}$ to a constant weight in an aluminum box and weighed to determine the acid-insoluble lignin (AIL) content. Acid-soluble lignin (ASL) was determined by the BlueStar A Spectrophotometer (Beijing LabTech Instrument Co., Ltd., Beijing, China). Glucose, xylose, and formic acid in supernatants were analyzed on an UltiMate-3000 HPLC (Thermo Fisher, Waltham, MA, USA) equipped with an Aminex HPX-87X column $(300 \mathrm{~mm} \times 7.8 \mathrm{~mm})$ and a RefractoMax521 refractive index detector. The mobile phase was $5 \mathrm{mM} \mathrm{H}_{2} \mathrm{SO}_{4}$ at a flow rate of $0.60 \mathrm{~mL} / \mathrm{min}$, and the column temperature was kept at $55^{\circ} \mathrm{C}$. The contents, puri- 
ties, and recoveries of cellulose, hemicellulose, and lignin were calculated according to Equations (1)-(8):

$$
\begin{gathered}
\text { Cellulose content }(\%)=\frac{W_{\text {Glc }} \times 0.9}{W_{O D S}} \times 100 \\
\text { Hemicellulose content }(\%)=\frac{W_{X y l} \times 0.88}{W_{O D S}} \times 100 \\
\text { Lignin content }(\%)=\frac{W_{A S L}+W_{A I L}}{W_{O D S}} \times 100 \\
\text { Cellulose purity }(\%)=\frac{\text { Weight }_{\text {Cellulose in crude cellulose }}}{\text { Weight }_{\text {Crude cellulose }}} \times 100 \\
\text { Lignin purity }(\%)=\frac{W_{\text {eight }} t_{\text {Total lignin in crude lignin }}}{\text { Weight }_{\text {Crude lignin }}} \times 100 \\
\text { Cellulose recovery }(\%)=\frac{\text { Weight }_{\text {Cellulose in crude cellulose }}}{\text { Weight }_{\text {Cellulose in feedstock }}} \times 100 \\
\text { Hemicellulose recovery }(\%)=\frac{\text { Weight }_{\text {Hemicellulose in extract }}}{\text { Weight }_{\text {Hemicellulose in feedstock }}} \times 100 \\
\text { Lignin recovery }(\%)=\frac{\text { Weight }_{\text {Lignin in crude lignin }}}{\text { Weight }_{\text {Lignin in feedstock }}} \times 100
\end{gathered}
$$

where $W_{G l c}, W_{X y l}, W_{A S L}, W_{A I L}$, and $W_{O D S}$ are the mass weight (g) of glucose, xylose, AcidSoluble Lignin (ASL), Acid-Insoluble Lignin (AIL), and oven-dry sample, respectively. The numbers of 0.9 and 0.88 are the correction factor, which were used to estimate the cellulose and hemicellulose content.

\subsection{Structure Analysis of Crude Cellulose and Lignin}

\subsubsection{Fourier Transform Infrared Spectral (FT-IR) Analysis}

FT - IR was used to characterize the changes in the functional groups of cellulose and lignin after the formic acid treatment. Crude cellulose, lignin, and $M L$ straw were mixed with dry potassium bromide $(\mathrm{KBr})$ at the mass ratio of about 1:100. After being ground in an agate mortar, the samples were pressed into slices under the action of a tableting machine and examined using a Nicolet iS5 FT-IR spectrometer (Thermo Fisher Technology Co., Ltd., Waltham, MA, USA) in the range of $4000-400 \mathrm{~cm}^{-1}$.

\subsubsection{X-ray Diffraction (XRD) Analysis}

The changes in crystallinity of cellulose caused by the formic acid treatment were determined by XRD. The crystalline phase of crude cellulose was demonstrated by a D8 Advance diffractometer (Bruck, Priyanka City, Germany). The spectra were recorded in a $2 \theta$ range of $5 \sim 50^{\circ}$ with $\mathrm{Cu} / \mathrm{K} \alpha$ radiation at $40 \mathrm{kV}$ and $40 \mathrm{~mA}$, with a stepping scanning speed of $6^{\circ} / \mathrm{min}$. The crystallinity index $(\mathrm{CrI})$ was calculated by the method reported by Segal et al. [25] using Equation (9).

$$
\operatorname{CrI}(\%)=\frac{I_{002}-I_{a m}}{I_{002}} \times 100
$$

where $I_{002}$ is for the highest peak intensity at $2 \theta=22.6^{\circ}$, and $I_{a m}$ is the intensity diffraction for amorphous cellulose at $2 \theta=18.0^{\circ}$.

\subsubsection{Scanning Electron Microscope (SEM) Analysis}

The morphological changes in the crude cellulose after formic acid treatment were characterized by SEM. Crude cellulose and ML straw were adhered to the sample stage. After being coated by spraying gold, the samples were visualized using a JSM-6380LV SEM (JEOL Co., Ltd., Tokyo, Japan) under an energy of $20 \mathrm{kV}$. 


\subsubsection{Thermogravimetry (TG) and Differential Thermogravimetry (DTG) Analysis}

TG and DTG properties of crude lignin were assessed with a TGA Q50 thermogravimetric analyzer (Waters Co., Milford, MA, USA). An amount of $6 \mathrm{mg}$ of crude lignin was loaded into alumina pans, where it was gradually heated from 30 to $650{ }^{\circ} \mathrm{C}$ at a heating rate of $10{ }^{\circ} \mathrm{C} / \mathrm{min}$. The flow rate of $\mathrm{N}_{2}$ was $40 \mathrm{~mL} / \mathrm{min}$.

\subsection{Determination of Monosaccharide Compositions in Hemicellulose Extract}

The hemicellulose extract was concentrated and dried, and $20 \mathrm{mg}$ of the dried sample was hydrolyzed with $3 \mathrm{M}$ TFA for $4 \mathrm{~h}$. The hydrolysate was evaporated to dryness, incubated with $200 \mu \mathrm{L}$ of $\mathrm{Na}_{2} \mathrm{CO}_{3}$ at $30^{\circ} \mathrm{C}$ in a dry bath for $45 \mathrm{~min}$, and reacted with $1 \mathrm{~mL}$ of $\mathrm{NaBH}_{4}$ at room temperature for $1.5 \mathrm{~h}$. The excess $\mathrm{NaBH}_{4}$ was removed by dropwise-adding $25 \%$ acetic acid. The reaction solution was added with $5 \mathrm{~mL}$ of anhydrous methanol, rotaryevaporated to dryness, and reconstituted with $5 \mathrm{~mL}$ of anhydrous methanol. The final residue was dried at $85^{\circ} \mathrm{C}$ for $2 \mathrm{~h}$, aminated with n-propylamine, and evaporated to dryness at $60^{\circ} \mathrm{C}$. The residue was further acetylated with acetic anhydride for $1 \mathrm{~h}$ and the reaction was terminated with $15 \mathrm{~mL}$ of deionized water and $3 \mathrm{~mL}$ of chloroform. The compositions were analyzed with a QP2010-plus GC-MS (Shimadzu, Kyoto, Japan) consisting of an RXI-5 SIL MS column $(30 \mathrm{~mm} \times 0.25 \mathrm{~mm} \times 0.25 \mathrm{~mm})$. The oven temperature started at $120^{\circ} \mathrm{C}$ and was programmed to immediately rise by $3{ }^{\circ} \mathrm{C} / \mathrm{min}$ to $250^{\circ} \mathrm{C}$; this final temperature was maintained for $5 \mathrm{~min}$. The inlet and detector temperatures were $250^{\circ} \mathrm{C}$, and the helium flow rate was $1 \mathrm{~mL} / \mathrm{min}$.

\subsection{Decolorization of Crude Xylose Extract}

Activated carbon pretreatment: the granular activated carbon was washed with deionized water, soaked in 3 volumes of $1 \mathrm{~mol} / \mathrm{L} \mathrm{HCl}$ for $12 \mathrm{~h}$, filtered, washed with deionized water to neutral, and dried at $105^{\circ} \mathrm{C}$ for $8 \mathrm{~h}$.

Decoloring treatment: $40 \mathrm{~mL}$ of crude xylose extract was added to pre-treated activated carbon, and the activated carbon content was $30 \mathrm{~g} / \mathrm{L}$. The decolorization was conducted at a $\mathrm{pH}$ of 2.87 and a temperature of $70{ }^{\circ} \mathrm{C}$ under constant shaking at a speed of $130 \mathrm{rpm}$ for $70 \mathrm{~min}$. The influence of activated carbon decolorization on the main components and decolorization rate of xylose was investigated. The OD value of xylose before and after decolorization was recorded, and the contents of xylose, glucose, arabinose, and formic acid were measured as described in Section 2.3.

\subsection{Purification of Crude Xylose Extract}

\subsubsection{Effect of Resin Static Adsorption on Main Compositions of Xylose}

Seven pretreated resins $(10 \mathrm{~g})$ were respectively dispersed in $50 \mathrm{~mL}$ of xylose in glass flasks. The flasks were constantly shaken at $30{ }^{\circ} \mathrm{C}$ and $130 \mathrm{rpm}$ until the absorption was saturated. The resins were then rinsed with deionized water, filtered, and shaken in $50 \mathrm{~mL}$ of deionized water at $130 \mathrm{r} / \mathrm{min}$ at $30{ }^{\circ} \mathrm{C}$ until the desorption was complete. The adsorption solution and desorption solution were analyzed by HPLC for the contents of xylose, arabinose, glucose, and formic acid. The equilibrium adsorption capacity and desorption efficiency of resins were calculated by Equations (10) and (11), respectively.

$$
\begin{aligned}
& Q(\mathrm{mg} / \mathrm{g})=\frac{\left(C_{1}-C_{0}\right) \times V_{1}}{m} \\
& E(\%)=\frac{C \times V_{2}}{\left(C_{1}-C_{0}\right)} \times V_{1} \times 100
\end{aligned}
$$

where $Q$ is the equilibrium adsorption capacity of resins, $C_{1}$ is the initial concentration of target monosaccharides or formic acid in extract, $C_{0}$ is the target monosaccharides or formic acid concentration in extract after the adsorption reaches equilibrium, $V_{1}$ is the volume of extract $(\mathrm{mL}), m$ is the dry weight of resins $(\mathrm{g}), E$ is the desorption efficiency, $V_{2}$ is 
desorption solution volume $(50 \mathrm{~mL})$, and $C$ is the content of monosaccharides or formic acid in desorption solution.

\subsubsection{Separation Effect of Dowex 50wx4 Resin on Xylose and Arabinose}

The pre-treated and transformed Dowex 50wx4 resin was poured into the chromatography column with a small amount of deionized water, and the resins were allowed to settle until no obvious faults and bubbles were found. An amount of $10 \mathrm{~mL}$ of xylose $(6.5 \mathrm{mg} / \mathrm{mL})$ was injected into the upper port of the chromatography column using a BT100L constant current pump (Baoding Leadfluid Fluid Technology Co., Ltd., Baoding City, China) at a flow rate of $1 \mathrm{~mL} / \mathrm{min}$ for dynamic adsorption. The adsorbed components were then eluted with deionized water at a flow rate of $1.5 \mathrm{~mL} / \mathrm{min}$ at $40^{\circ} \mathrm{C}$. The packed resin length was $40 \mathrm{~cm}$ and the eluate between 50 and $80 \mathrm{~cm}$ was collected and analyzed by HPLC to evaluate the separation efficiency of the Dowex 50wx4 resin for xylose and arabinose.

\subsection{Statistical Analysis}

The data were analyzed by Origin 2019b and SPSS 19 and statistical significance was determined using Duncan's multiple range test $(p<0.05)$. The final data were expressed as average $\pm \mathrm{SD}$.

\section{Results}

\subsection{Analysis of Compositions of Crude Cellulose and Lignin}

The recoveries of cellulose, hemicellulose, and lignin obtained by formic acid were $91.7 \%, 80.2 \%$, and $85.3 \%$, respectively. The material balance calculation showed that the three components obtained after formic acid treatment were more than $87 \%$ compared to the original content in the $M L$ straw. From Table 1, the cellulose content of crude cellulose and the total lignin content of crude lignin were $83.6 \%$ and $86.8 \%$, respectively, which were significantly higher than those in $M L$ straw. Meanwhile, more than $95 \%$ formic acid with the concentration of $87.58 \%$ can be recovered by rotary evaporation. The verification test showed the separation effect of recovered formic acid on lignocellulose, which was not significantly different from the above results. These results demonstrated that the formic acid method was a green and efficient method for the separation of lignocellulose and recycling of formic acid.

Table 1. The contents of main components of crude cellulose and lignin.

\begin{tabular}{ccccc}
\hline \multirow{2}{*}{ Samples } & \multicolumn{4}{c}{ Contents (\%) } \\
\cline { 2 - 5 } & Cellulose & Hemicellulose & ASL & AIL \\
\hline ML straw & $41.89 \pm 0.73^{\mathrm{b}}$ & $18.21 \pm 0.42^{\mathrm{a}}$ & $2.53 \pm 0.04^{\mathrm{a}}$ & $16.77 \pm 0.18^{\mathrm{b}}$ \\
Crude cellulose & $83.60 \pm 0.15^{\mathrm{a}}$ & $5.15 \pm 0.05^{\mathrm{b}}$ & $0.50 \pm 0.02^{\mathrm{c}}$ & $6.35 \pm 0.27^{\mathrm{c}}$ \\
Crude lignin & $2.20 \pm 0.26^{\mathrm{c}}$ & $3.86 \pm 0.11^{\mathrm{c}}$ & $1.40 \pm 0.01^{\mathrm{b}}$ & $85.40 \pm 0.68^{\mathrm{a}}$ \\
\hline
\end{tabular}

The same letters show the homogeneous groups.

\subsection{FT-IR Analysis of Crude Cellulose and Lignin}

The FT-IR spectrum of crude cellulose and lignin (Figure 2) showed that the absorption peaks at $3391 \mathrm{~cm}^{-1}$ and $2895 \mathrm{~cm}^{-1}$ were attributed to the $\mathrm{O}-\mathrm{H}$ stretching vibration of an hydroxyl group and the $\mathrm{C}-\mathrm{H}$ stretching vibration of an aromatic methyl group, respectively. After formic acid treatment, the intensity of this absorption peak in the crude cellulose increased significantly, indicating that the cellulose content increased, and the degradation degree of formic acid on cellulose was low [26]. The characteristic peak at $1720 \mathrm{~cm}^{-1}$ was caused by $\mathrm{C}=\mathrm{O}$ stretching vibration of a nonconjugated carbonyl group. The absorption peak became significantly stronger after the formic acid treatment, indicating that formic acid had a strong formylation modification with $-\mathrm{OH}$ on the structure of the crude cellulose [21]. Compared with $M L$ straw, the benzene-skeleton absorption peak intensity of crude cellulose was weakened at $1603 \mathrm{~cm}^{-1}, 1513 \mathrm{~cm}^{-1}$, and $1425 \mathrm{~cm}^{-1}$, 
indicating that formic acid could effectively separate cellulose and lignin and significantly improve the purity of crude cellulose [27]. The disappearance of the peak at $1251 \mathrm{~cm}^{-1}$ was attributed to the removal of lignin after formic acid treatment [28]. The $\mathrm{C}-\mathrm{H}$ symmetrical bending of cellulose at $1325 \mathrm{~cm}^{-1}$, and the $\mathrm{C}-\mathrm{O}-\mathrm{C}$ and $\mathrm{C}=\mathrm{O}$ stretching vibrations of cellulose at $1163 \mathrm{~cm}^{-1}$ and $1060 \mathrm{~cm}^{-1}$ corresponded to the asymmetric $\mathrm{C}-\mathrm{O}-\mathrm{C}$ stretching vibration and $\mathrm{C}=\mathrm{O}$ stretching vibration of cellulose, respectively, indicating that the basic results of cellulose remained intact after formic acid treatment [29]. The ratio of absorbance at $1431 \mathrm{~cm}^{-1}$ and $897 \mathrm{~cm}^{-1}\left(\mathrm{~A}_{1431} / \mathrm{A}_{897}\right)$ raised suggested that the crystallinity of the crude cellulose separated by formic acid increased compared with that of $M L$ straw.

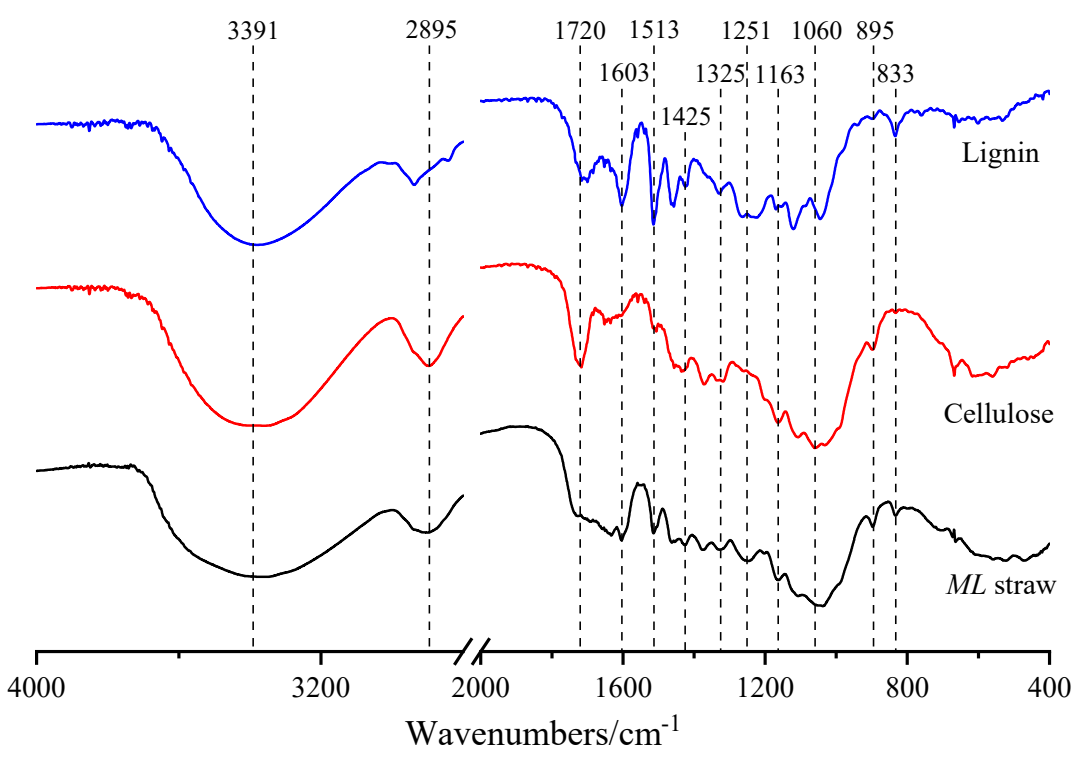

Figure 2. FT-IR spectra of $M L$ crude cellulose and lignin before and after formic acid treatment.

The stretching vibration peak of lignin-OH was located at $3391 \mathrm{~cm}^{-1}$, and the ratio of $\mathrm{A}_{3411} / \mathrm{A}_{1513}$ was relatively low, indicating that the content of hydroxyl in lignin was less. The vibration peaks of the aromatic ring skeleton at $1603 \mathrm{~cm}^{-1}, 1513 \mathrm{~cm}^{-1}$, and $1425 \mathrm{~cm}^{-1}$ showed strong absorption peaks. Therefore, it was speculated that not only was the purity of the crude lignin treated with formic acid high, but the benzene ring structure was also not damaged [30]. At $1720 \mathrm{~cm}^{-1}$, there was a stretching vibration of ester group nonconjugated carbonyl $\mathrm{C}=\mathrm{O}$, where the peak value was strong because formic acid treatment also leads to the formylation of lignin. The characteristic absorption peak at $1462 \mathrm{~cm}^{-1}$ was $\mathrm{C}-\mathrm{H}$ bending vibration connected by benzene rings, the peak at $1121 \mathrm{~cm}^{-1}$ was $\mathrm{C}-\mathrm{H}$ plane deformation vibration in the syringyl ring, and the peaks at $1033 \mathrm{~cm}^{-1}$ and $833 \mathrm{~cm}^{-1}$ were $\mathrm{C}-\mathrm{H}$ plane deformation vibration in the guaiacyl ring, respectively. The absorption peaks at $1266 \mathrm{~cm}^{-1}$ and $1170 \mathrm{~cm}^{-1}$ were of $\mathrm{C}=\mathrm{O}$ stretching vibration in the guaiacyl ring and $\mathrm{C}=\mathrm{O}$ stretching vibration of the para-hydroxy-phenyl structure, respectively, which indicated that the crude lignin in $M L$ is a typical GSH-type lignin [31].

\subsection{XRD Analysis of Crude Cellulose}

From the results presented in Figure 3, there were three obvious diffraction peaks at $2 \theta=15.67^{\circ}, 22.38^{\circ}$, and $34.81^{\circ}$, and there were no double peaks near $2 \theta=22^{\circ}$, indicating that the structure of $M L$ crude cellulose was type I [32]. The formic acid treatment did not change the cellulose configuration but slightly shifted the characteristic peaks because the removal of lignin and hemicellulose changed the hydrogen bonding between the cellulose chains [33]. Crystallinity index (CrI) is an important technological parameter in the subsequent steps of cellulose hydrolysis, which is directly related to the accessibility of enzyme-cellulose. A higher $\mathrm{CrI}$ leads to a better separation efficiency of the formic acid treatment [9]. Combined with Equation (9), it was found that the CrI of the $M L$ straw was 
$51.34 \%$, and after dealing with the formic acid, the $\mathrm{CrI}$ of crude cellulose increased to $70.14 \%$. It can be explained that cellulose was isolated from the lignin and hemicellulose by the formic acid treatment and the content of crystalline cellulose significantly increased after the lignin and hemicellulose were removed [16]. After formic acid treatment, the hydrogen bond in the amorphous region of cellulose increased, which enhanced the order of the crystallization region. The improvement of crystallinity is beneficial to its application in functional materials such as electronic devices, reinforced composites, edible antibacterial films, and sensors.

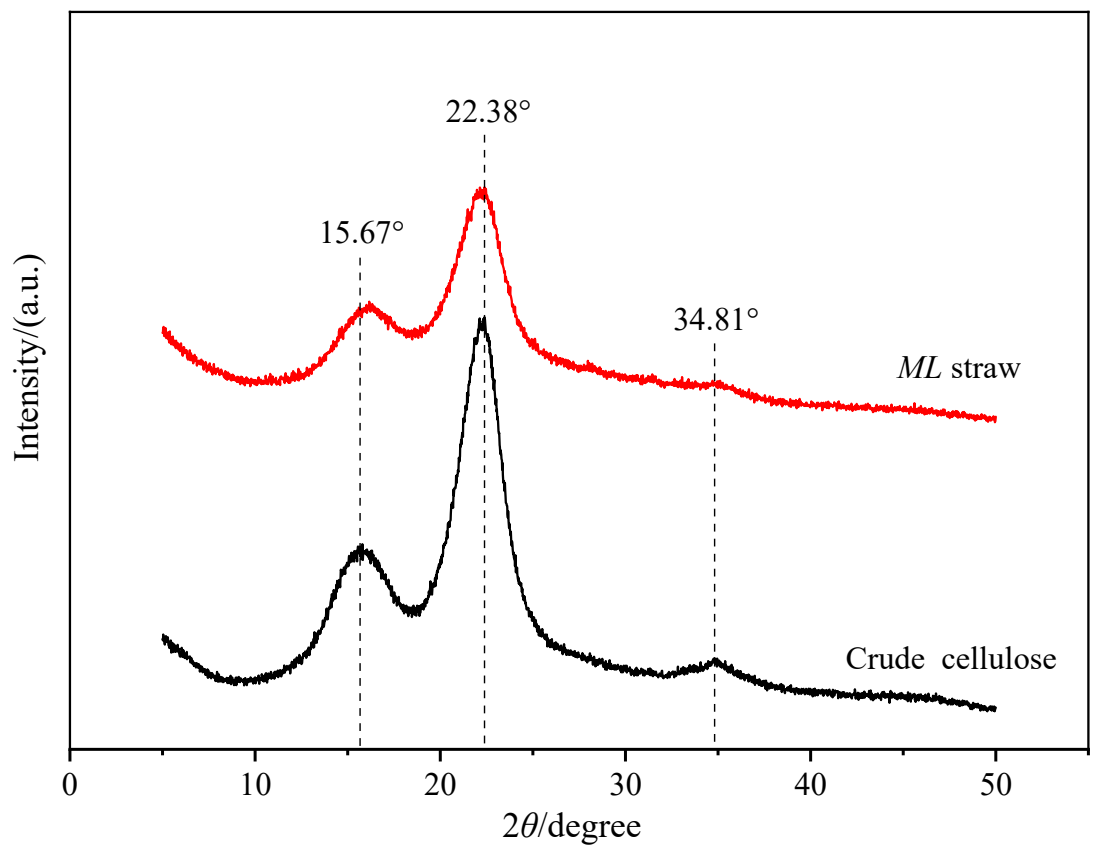

Figure 3. XRD image of $M L$ crude cellulose before and after formic acid treatment.

\subsection{SEM Analysis of Crude Cellulose}

Figure 4 shows SEM images of $M L$ straw and crude cellulose at a magnification of 2000 and 500 times. The $M L$ straw without formic acid treatment had a relatively complete structure and a relatively smooth surface. The surfaces of the crude cellulose were rough, with larger cracks and fragmented structures, indicating that the formic acid treatment destroyed the surface structure of the straw. Formic acid could dissolve most of the lignin on the straw surface. The embedding effect of lignin was weakened, and more available active sites of the biomass were exposed to bind cellulose, which facilitated the hydrolysis and utilization of cellulose [9]. Li et al. [21] also reported similar observations on the treatment of bamboo lignocellulose with formic acid.

\subsection{TGA Analysis of Crude Lignin}

Thermal analysis is an important means to evaluate the physical and chemical properties of lignin. The TG curves and DTG curves of crude lignin are shown in Figure 5, which are mainly divided into three stages. The initial weight loss of $5 \%$ was found in the range of $30 \sim 160^{\circ} \mathrm{C}$, which was mainly caused by the evaporation of external water and bound water of lignin. The thermal decomposition mainly occurred at $160 \sim 480{ }^{\circ} \mathrm{C}$, which caused a weight loss up to $55 \%$. At this stage, lignin underwent a dehydration reaction and rapidly decomposed into small monomers. The benzene ring structure of lignin decomposed at the third stage as the temperature increased to over $480^{\circ} \mathrm{C}$. Lignin is a relatively stable structure (GSH type) formed by cross-linking guaiacyl, syringyl, para-hydroxy-phenyl, and other functional groups. It exhibited very good thermal stability with $29 \%$ solid residue after the decomposition at $650{ }^{\circ} \mathrm{C}$. It has promising applications in the production of materials such as composite sheets with biological durability and thermal stability [27]. 


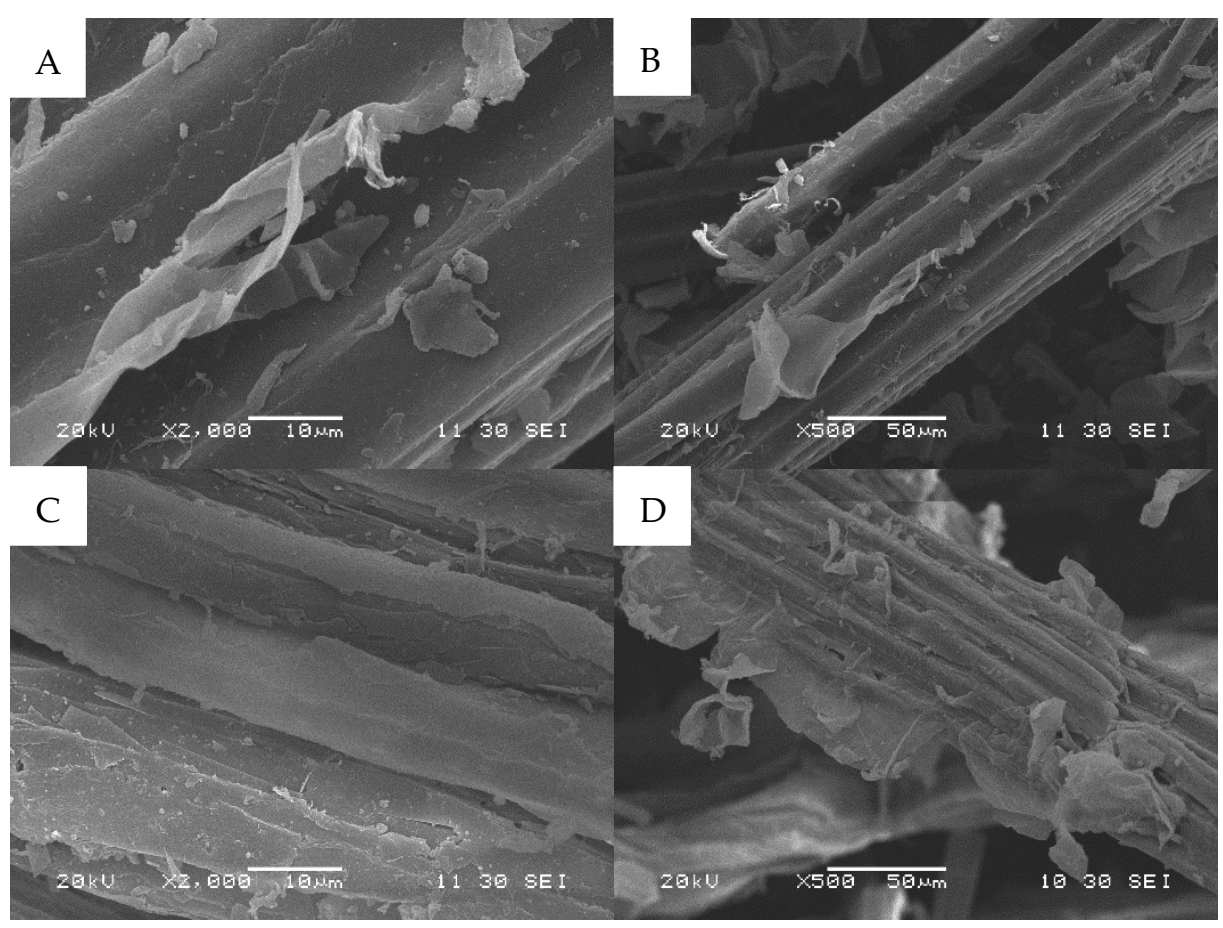

Figure 4. SEM images of crude cellulose before and after formic acid treatment. $(\mathbf{A}, \mathbf{B}) M L$ straw at magnifications of $2000 \times$ and $500 \times$, respectively; (C,D) crude cellulose at magnifications of $2000 \times$ and $500 \times$, respectively.

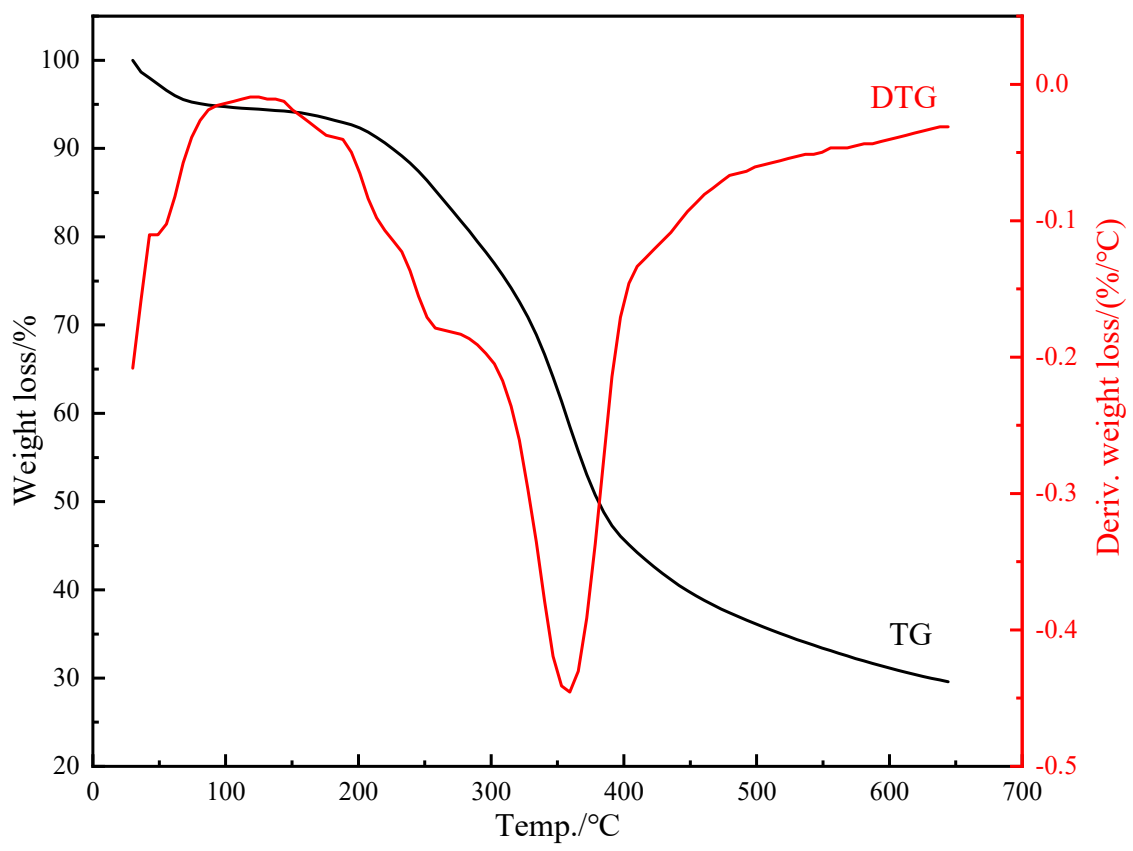

Figure 5. TG and DTG image of crude lignin.

\subsection{Composition Analysis of Hemicellulose Extract}

GC-MS was used to analyze the monosaccharide compositions of the separated hemicellulose, and the results are shown in Table 2 and Figure 6. As can be seen from Table 2, xylose was the main component in hemicellulose, and the content was as high as $74.89 \%$, while the content of other monosaccharides was relatively low, suggesting that the high-temperature formic acid extraction can hydrolyze the hemicellulose and the main component of the hemicellulose extract is xylose. HPLC analysis revealed that the 
hemicellulose extract was still doped with $39.06 \%$ formic acid, which could be attributed to the solvent residue at the rotary evaporation stage. By calculation, the extraction rate of xylose in the crude extract of xylose prepared by this method was $89.80 \%$, indicating that the formic acid treatment can well separate the components of lignocellulose of $M L$ and hydrolyze the hemicellulose into monosaccharides simultaneously. The hemicellulose extract can be directly used as the stock solution of high-purity xylose.

Table 2. The contents of monosaccharide components of hemicellulose extract.

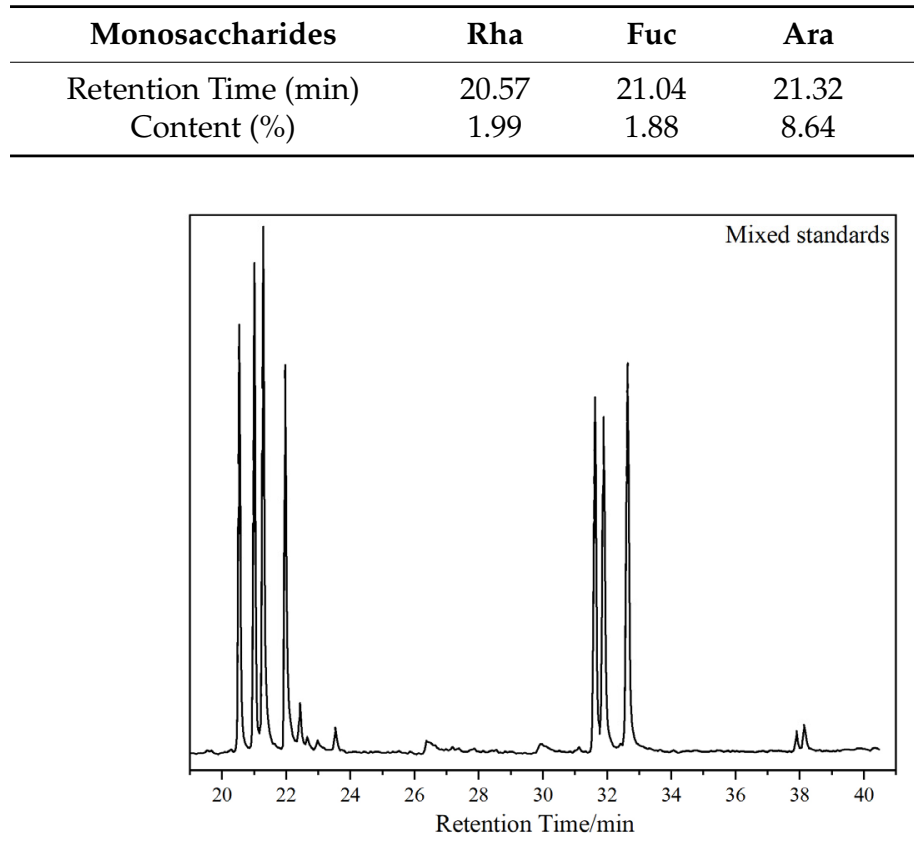

\begin{tabular}{cccccc} 
Xyl & Man & Glc & Gal & GlcA & GalA \\
\hline 22.00 & 31.64 & 31.91 & 32.65 & 37.91 & 38.13 \\
74.89 & 1.82 & 5.42 & 3.73 & 0.84 & 0.79 \\
\hline
\end{tabular}

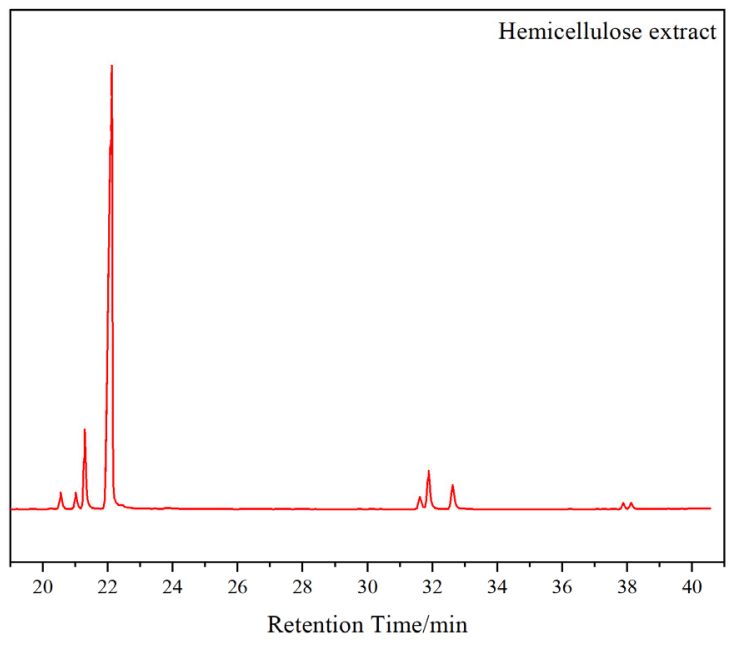

Figure 6. GC-MS chromatogram of hemicellulose extract.

\subsection{Decolorization on Crude Xylose Extract with Activated Carbon}

Due to the color reaction of raw materials in the hydrolysis process and the presence of residual lignin in the hydrolysate, the hydrolysate appears orange-brown. The color substances in the hydrolysate are mainly the products of pigments, caramelization reaction, Maillard reaction, and acid degradation reaction of reducing monosaccharides. The surface of activated carbon particles contains a large number of pores, which can absorb pigment molecules whose molecular weight in xylose crude extract is equivalent to the pore size of activated carbon, and has a strong adsorption effect on the pigment molecules with aromatic rings [34].

According to Figure 7, the main components of crude xylose extract before and after decolorization were xylose and formic acid. Combined with Table 3, it was found that the proportion of main components in crude xylose extract basically did not change, indicating that activated carbon treatment only removed a large number of pigments in xylose $(93.66 \%)$, and had similar adsorption capacities for the main components in the extract. Therefore, the granular activated carbon was suitable for decolorization of xylose crude extract, but other methods should be considered for further removal of residual formic acid.

Table 3. Changes in the main components of xylose before and after decolorization.

\begin{tabular}{|c|c|c|c|c|c|c|}
\hline \multirow{2}{*}{ Treatment } & \multicolumn{4}{|c|}{ Content (\%) } & \multirow{2}{*}{$\begin{array}{c}\text { Retention Rate of } \\
\text { Xylose }(\%)\end{array}$} & \multirow{2}{*}{$\begin{array}{c}\text { Decolorization } \\
\text { Rate of Xylose (\%) }\end{array}$} \\
\hline & Xylose & Arabinose & Glucose & Formic Acid & & \\
\hline Formic acid & 55.00 & 5.14 & 0.80 & 39.06 & 89.80 & - \\
\hline Decolorization & 54.22 & 5.18 & 0.86 & 39.76 & 88.58 & 93.66 \\
\hline
\end{tabular}




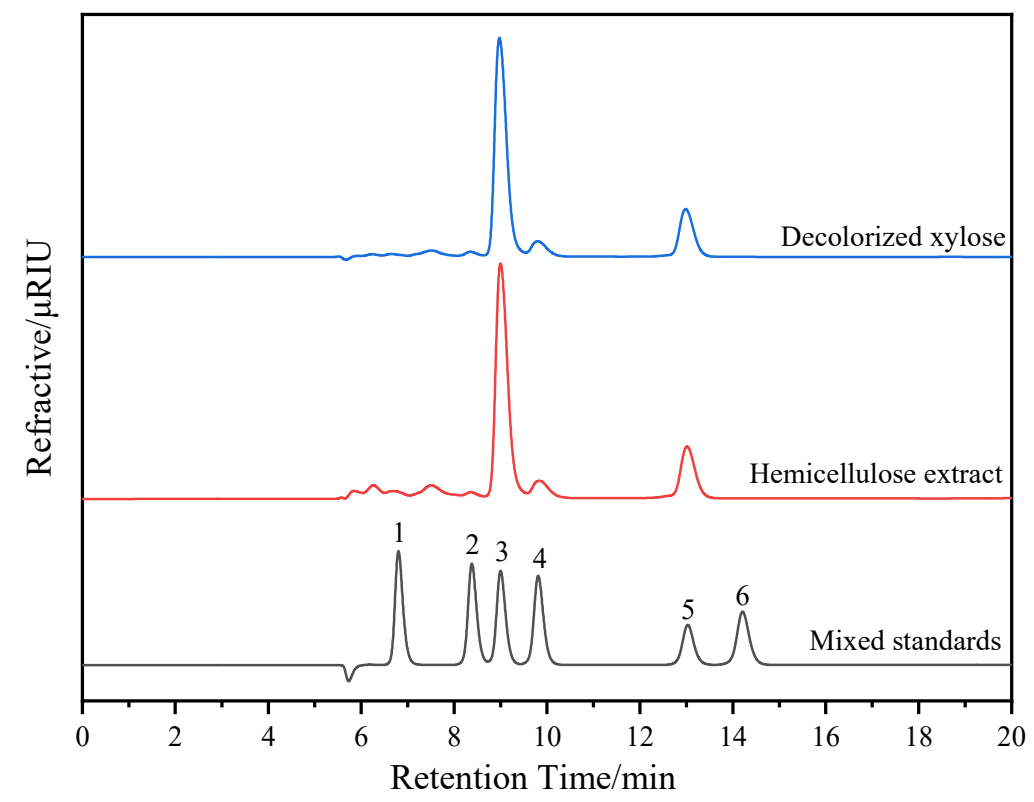

Figure 7. HPLC of the decolorized xylose solution. 1-Fibrous disaccharides; 2-glucose; 3-xylose; 4-arabinose; 5-formic acid; 6-acetic acid. The numeric codes in Figure 8 have the same meaning.

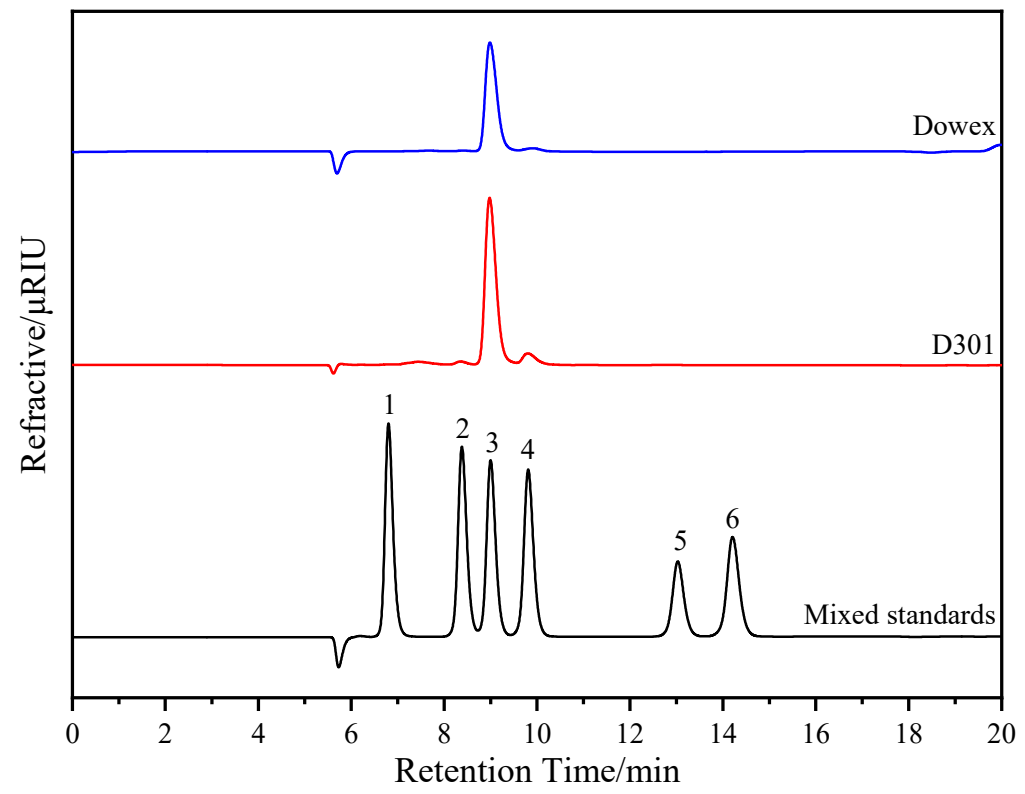

Figure 8. HPLC of the resin-treated xylose solution. D301 and Dowex represent the xylose solution treated with D301 and Dowex 50wx4 resin, respectively.

\subsection{Purification of Crude Xylose Extract}

\subsubsection{Screening Results of Static Adsorption of Resins}

The composition of the crude xylose extract is very complicated. It contains a variety of compounds, such as residual formic acid, other monosaccharides, hetero-proteins, and salts ions, in addition to large amounts of pigments. In order to obtain high-purity xylose, the above impurities should be removed as much as possible. As can be seen from Table 4, the adsorption capacities of D201, D301, and D311 anions on monosaccharides and formic acid were relatively large, especially the last two. It can be explained that both D301 and D311 are weakly basic, and their alkaline groups can neutralize the formic acid in the extract, showing good exchange capacities for formic acid. All resins showed similar absorption 
and desorption capacities for xylose and arabinose (Table 5) because they are isomers with strong polarities. The similar structures and similar solubilities of xylose and arabinose make them very challenging to separate with resins. D301 showed the highest desorption efficiencies for both xylose and arabinose. The formic acid desorption efficiencies of all resins were relatively low, which is beneficial to the formic acid removal from the xylose extract. In particular, more than $99 \%$ of the formic acid were adsorbed by D301 and D311, and the adsorbed formic acid on these two resins could not be eluted with deionized water. After comprehensive considerations, D301 was selected to deacidify and purify the xylose extract. To improve the experiment efficiency, the xylose extract after being treated by D301 resin was directly used for the study on the removal of other monosaccharide impurities

Table 4. Static adsorption of monosaccharides and formic acid from xylose by resins.

\begin{tabular}{|c|c|c|c|c|}
\hline \multirow{2}{*}{ Resin Type } & \multicolumn{4}{|c|}{ Content (mg/g) } \\
\hline & Glu & Ara & Xyl & Formic Acid \\
\hline D201 & $0.13 \pm 0.00^{b, c}$ & $0.68 \pm 0.07^{a}$ & $8.13 \pm 0.06^{a}$ & $36.80 \pm 0.63^{c}$ \\
\hline D301 & $0.28 \pm 0.09^{a}$ & $0.59 \pm 0.00^{b}$ & $7.68 \pm 0.34^{b}$ & $62.77 \pm 0.92^{b}$ \\
\hline D311 & $0.30 \pm 0.08^{a}$ & $0.52 \pm 0.03^{c, d}$ & $7.43 \pm 0.08^{b}$ & $67.43 \pm 0.20^{a}$ \\
\hline 717 & $0.05 \pm 0.00^{c}$ & $0.50 \pm 0.02^{c, d}$ & $6.49 \pm 0.08^{d}$ & $36.76 \pm 0.11^{\mathrm{c}}$ \\
\hline D113 & $0.15 \pm 0.00^{b, c}$ & $0.56 \pm 0.02^{b, c}$ & $5.43 \pm 0.08^{\mathrm{e}}$ & $4.63 \pm 0.09 \mathrm{e}$ \\
\hline 732 & $0.21 \pm 0.00^{a, b}$ & $0.46 \pm 0.04^{\mathrm{d}}$ & $3.86 \pm 0.13^{f}$ & $6.17 \pm 0.14^{d}$ \\
\hline 734 & $0.22 \pm 0.09^{a, b}$ & $0.51 \pm 0.01^{\mathrm{c}, \mathrm{d}}$ & $6.86 \pm 0.23^{c}$ & $6.34 \pm 0.04^{d}$ \\
\hline
\end{tabular}

Note: There are significant difference in the same column with different letters $(p<0.05)$.

Table 5. Static resolving rate of monosaccharides and formic acid in xylose by resins.

\begin{tabular}{ccccc}
\hline \multirow{2}{*}{ Resin Type } & Glu & Ara & Xesolving Rate (\%) & Formic Acid \\
\cline { 2 - 5 } & $47.25 \pm 0.69^{\mathrm{b}}$ & $73.88 \pm 0.24^{\mathrm{e}}$ & $77.12 \pm 1.58^{\mathrm{d}}$ & $10.91 \pm 0.65^{\mathrm{d}}$ \\
\hline D201 & $20.19 \pm 0.64^{\mathrm{d}}$ & $96.89 \pm 0.70^{\mathrm{a}}$ & $91.35 \pm 1.17^{\mathrm{a}}$ & $0.71 \pm 0.03^{\mathrm{f}}$ \\
\hline D301 & $22.45 \pm 0.50^{\mathrm{c}}$ & $93.68 \pm 0.46^{\mathrm{b}}$ & $81.21 \pm 1.60^{\mathrm{c}}$ & $0.57^{\mathrm{b}} \pm 0.00^{\mathrm{f}}$ \\
\hline D311 & $83.19 \pm 1.54^{\mathrm{a}}$ & $74.15 \pm 0.92^{\mathrm{e}}$ & $73.53 \pm 0.45^{\mathrm{e}}$ & $6.42^{\mathrm{a}} \pm 0.24^{\mathrm{e}}$ \\
\hline 717 & $19.40 \pm 0.96^{\mathrm{d}}$ & $45.63 \pm 1.35^{\mathrm{f}}$ & $59.71 \pm 1.93^{\mathrm{f}}$ & $50.15 \pm 1.12^{\mathrm{c}}$ \\
\hline D113 & $6.30 \pm 0.06^{\mathrm{e}}$ & $78.58 \pm 0.76^{\mathrm{d}}$ & $88.65 \pm 1.16^{\mathrm{b}}$ & $70.40 \pm 0.28^{\mathrm{b}}$ \\
\hline 732 & $19.19 \pm 0.14^{\mathrm{d}}$ & $84.15 \pm 0.32^{\mathrm{c}}$ & $89.53 \pm 1.45^{\mathrm{a}, \mathrm{b}}$ & $74.42 \pm 0.24^{\mathrm{a}}$ \\
\hline 734 & $N$ &
\end{tabular}

Note: There are significant difference in the same column with different letters $(p<0.05)$.

\subsubsection{Analysis Results of Xylose Purity before and after Resin Treatment}

Table 6 shows the main components in the xylose extract after the treatments with D301 and Dowex 50wx4. The adsorption and desorption with D301 increased the xylose content to $86.34 \%$ with a recovery over $96.8 \%$. The arabinose and glucose contents in the treated extract were $7.77 \%$ and $1.90 \%$, respectively, and formic acid was almost completely removed. These results suggest that D301 can be applied to the purification of xylose extract prepared by the formic acid treatment of lignocellulose. Zdarta et al. [35] also reported the high-efficiency removal of acetic acid and furfural from the hydrolysate of birch for the purification of xylose that gave a xylose purity and recovery up to $90 \%$ and $99 \%$, respectively. 
Table 6. Main components of xylose solution after resin treatment.

\begin{tabular}{ccccccc}
\hline \multirow{2}{*}{ Resin Treatment } & \multicolumn{3}{c}{ Content (\%) } & \multirow{2}{*}{ Recovery Rate of Xylose (\%) } \\
\cline { 2 - 6 } & Xylose & Arabinose & Glucose & Formic Acid & Others & 96.80 \\
\hline D301 & 86.34 & 7.77 & 1.90 & 0.11 & 3.88 & 84.00 \\
\hline
\end{tabular}

Cation exchange resin has a good adsorption capacity for arabinose [36]. As shown in Figure 8, the extract treated with Dowex 50wx4 resin showed a single peak of xylose. The xylose content significantly increased to $95.01 \%$ (Table 6) and the arabinose content decreased to $1.7 \%$. The contents of glucose and other monosaccharides also significantly reduced. These results suggest the good separation efficiency of the resin for the monosaccharides, and Dowex 50wx4 cation exchange resin can be used to remove saccharide impurities from the xylose extract obtained by the formic acid treatment of $M$. Lutarioriparia straw.

\section{Conclusions}

In summary, these findings demonstrate that the formic acid method can be used to separate lignocellulosic components of $M$. Lutarioriparia and hydrolyze hemicellulose simultaneously. Furthermore, activated carbon for removing pigments, D301 resin for removing formic acid, and Dowex 50wx4 resin for separating arabinose and xylose are all effective methods for xylose purification. The results provide a new method for the effective separation of components and the preparation of xylose, which has broad application prospects in the field of biorefining lignocellulosic resources. However, the practical application of the entire formic acid treatment process should still be discussed for its economic feasibility and product practicality, which is under consideration in our laboratory.

Author Contributions: Conceptualization, J.O., X.-F.W. and X.-J.S.; methodology, W.-Q.H., Q.-M.L. and X.-F.W.; formal analysis, J.O., Q.-M.L. and L.C.; data curation, J.O. and W.-Q.H.; writing-original draft preparation, J.O. and W.-Q.H.; writing-review and editing, X.-F.W. and X.-J.S.; visualization, X.-J.S.; funding acquisition, X.-J.S. All authors have read and agreed to the published version of the manuscript.

Funding: This work was supported by a special project for the construction of innovative provinces in Hunan Province of China (grant number 2019NK2031-2).

Institutional Review Board Statement: The study did not involve humans or animals.

Informed Consent Statement: The study did not involve humans.

Data Availability Statement: The study did not report any data.

Conflicts of Interest: The authors declare no conflict of interest.

\section{References}

1. Tian, D.; Hu, J.G.; Bao, J.; Chandra, R.P.; Saddler, J.N.; Lu, C.H. Lignin valorization: Lignin nanoparticles as high-value bio-additive for multifunctional nanocomposites. Biotechnol. Biofuels 2017, 10, 192. [CrossRef] [PubMed]

2. Walter, D.; Sharma, V.K.; Mengshan, L.; Govind, N.; Varma, R.S. Lignocellulosic Biomass Transformations via Greener Oxidative Pretreatment Processes: Access to Energy and Value-Added Chemicals. Front. Chem. 2018, 6, 141. [CrossRef]

3. Shi, Y.F.; Du, X.H.; Jin, M.T.; Wu, S.; Wang, L.; Qiao, N.; Yu, D.Y. A two-step process for pre-hydrolysis of hemicellulose in pulp-impregnated effluent with high alkali concentration to improve xylose production. J. Hazard. Mater. 2021, $402,123573$. [CrossRef] [PubMed]

4. Arora, S.; Gupta, N.; Singh, V. pH-Controlled Efficient Conversion of Hemicellulose to Furfural Using Choline-Based Deep Eutectic Solvents as Catalysts. ChemSusChem 2021, 14, 3953-3958. [CrossRef] [PubMed]

5. Verdini, F.; Gaudino, E.C.; Grillo, G.; Tabasso, S.; Cravotto, G. Cellulose Recovery from Agri-Food Residues by Effective Cavitational Treatments. Appl. Sci. 2021, 11, 4693. [CrossRef]

6. Prasad, R.K.; Chatterjee, S.; Mazumder, P.B.; Gupta, S.K.; Sharma, S.; Vairale, M.G.; Datta, S.; Dwivedi, S.K.; Gupta, D.K. Bioethanol production from waste lignocelluloses: A review on microbial degradation potential. Chemosphere 2019, 231, 88-606. [CrossRef] 
7. Huang, J.W.; Zhu, Y.K.; Liu, T.Y.; Sun, S.L.; Ren, J.L.; Wu, A.M.; Li, H.L. A novel wet-mechanochemical pretreatment for the efficient enzymatic saccharification of lignocelluloses: Small dosage dilute alkali assisted ball milling. Energy Convers. Manag. 2019, 194, 46-54. [CrossRef]

8. Gschwend, F.J.V.; Chambon, C.L.; Biedka, M.; Brandt-Talbot, A.; Fennell, P.S.; Hallett, J.P. Quantitative glucose release from softwood after pretreatment with low-cost ionic liquids. Green Chem. 2019, 21, 692-703. [CrossRef]

9. Sahoo, D.; Ummalyma, S.B.; Okram, A.K.; Pandey, A.; Sankar, M.; Sukumaran, R.K. Effect of dilute acid pretreatment of wild rice grass (Zizania latifolia) from Loktak Lake for enzymatic hydrolysis. Bioresour. Technol. 2018, 253, 252-255. [CrossRef]

10. Hammerer, F.; Loots, L.; Do, J.L.; Therien, J.P.D.; Nickels, C.W.; Friščić, T.; Auclair, K. Solvent-Free Enzyme Activity: Quick, High-Yielding Mechanoenzymatic Hydrolysis of Cellulose into Glucose. Angew. Chem. Int. Ed. Engl. 2018, 130, $2651-2654$. [CrossRef]

11. Su, X.J.; Zhang, C.Y.; Li, W.J.; Wang, F.; Wang, K.Q.; Liu, Y.; Li, Q.M. Radiation-Induced Structural Changes of Miscanthus Biomass. Appl. Sci. 2020, 10, 1130. [CrossRef]

12. Zhao, X.B.; Liu, D.H. Multi-products co-production improves the economic feasibility of cellulosic ethanol: A case of Formiline pretreatment-based biorefining. Appl. Energy 2019, 250, 229-244. [CrossRef]

13. Zhang, M.J.; Qi, W.; Liu, R.; Su, R.X.; Wu, S.M.; He, Z.M. Fractionating lignocellulose by formic acid: Characterization of major components. Biomass Bioenergy 2010, 34, 525-532. [CrossRef]

14. Yu, Y.Y.; Xu, H.H.; Yu, H.F.; Hu, L.H.; Liu, Y. Formic acid fractination towards highly efficient cellulose-derived PdAg bimetallic catalyst for $\mathrm{H}_{2}$ evolution. Green Energy Environ. 2020, 7, 172-183. [CrossRef]

15. Jing, W.X.; Zhe, W. A Study on Catalytic Hydrolysis of Corncob by Formic Acid. Adv. Mater. Res. 2012, 560-561, 321-324. [CrossRef]

16. Jin, C.D.; Yang, M.; Shuang, E.; Liu, J.L.; Zhang, S.L.; Sheng, K.C.; Zhang, X.M. Corn stover valorization by one-step formic acid fractionation and formylation for 5-hydroxymethylfurfural and high guaiacyl lignin production. Bioresour. Technol. 2020, 299, 122586. [CrossRef] [PubMed]

17. Zhong, X.H.; Yuan, R.; Zhang, B.S.; Wang, B.; Chu, Y.Q.; Wang, Z.J. Full fractionation of cellulose, hemicellulose, and lignin in pith-leaf containing corn stover by one-step treatment using aqueous formic acid. Ind. Crop. Prod. 2021, 172, 113962. [CrossRef]

18. Tian, G.Y.; Xu, J.Y.; Fu, Y.J.; Guo, Y.Z.; Wang, Z.J.; Li, Q. High $\beta-O-4$ polymeric lignin and oligomeric phenols from flow-through fractionation of wheat straw using recyclable aqueous formic acid. Ind. Crop. Prod. 2019, 131, 142-150. [CrossRef]

19. Zhu, S.W.; Zhan, W.; Yu, H.F.; Liu, Y. Fractionation of lignin and cellulose from Pterocarpus macarocarpus Kurz using formic acid J. Beijing Univ. Chem. Technol. 2019, 46, 57-63. [CrossRef]

20. Zhang, Y.C.; Xu, W.Y.; Wang, X.J.; Ni, S.Z.; Rosqvist, E.; Smatt, J.H.; Peltonen, J.; Hou, Q.X.; Qin, M.H.; Willfor, S.; et al. From Biomass to Nanomaterials: A Green Procedure for Preparation of Holistic Bamboo Multifunctional Nanocomposites Based On Formic Acid Rapid Fractionation. ACS Sustain. Chem. Eng. 2019, 7, 6592-6600. [CrossRef]

21. Li, M.F.; Yu, P.; Li, S.X.; Wu, X.F.; Xiao, X.; Bian, J. Sequential two-step fractionation of lignocellulose with formic acid organosolv followed by alkaline hydrogen peroxide under mild conditions to prepare easily saccharified cellulose and value-added lignin. Energy Convers. Manag. 2017, 148, 1426-1437. [CrossRef]

22. Xu, Y.Z.; Fu, G.Y.; Tang, N.; He, Z.H.; Jian, L.C.; Zhao, Y.Y. Distribution of Triarrhena lutarioriparia and its reserve characteristics of nitrogen and phosphorus in Dongting Lake. E3S Web Conf. 2021, 237, 01004. [CrossRef]

23. Tao, X.; Li, J.; Zhang, P.Y.; Nabi, M.; Jin, S.G.; Li, F.; Wang, S.Q.; Ye, J.P. Reinforced acid-pretreatment of Triarrhena lutarioriparia to accelerate its enzymatic hydrolysis. Int. J. Hydrogen Energy 2017, 42, 18301-18308. [CrossRef]

24. Sluiter, A.; Hames, B.; Ruiz, R.; Scarlata, C.; Sluiter, J.; Templeton, D. Determination of Sugars, Byproducts, and Degradation Products in Liquid Fraction Process Samples. Available online: https://www.nrel.gov/docs/gen/fy08/42623.pdf (accessed on 2 September 2021).

25. Segal, L.; Creely, J.J.; Martin, A.E., Jr.; Conrad, C.M. An Empirical Method for Estimating the Degree of Crystallinity of Native Cellulose Using the X-ray Diffractometer. Text. Res. J. 1959, 29, 786-794. [CrossRef]

26. Li, P.; Cai, D.; Luo, Z.F.; Qin, P.Y.; Chen, C.J.; Wang, Y.; Zhang, C.W.; Wang, Z.; Tan, T.W. Effect of acid pretreatment on different parts of corn stalk for second generation ethanol production. Bioresour. Technol. 2016, 206, 86-92. [CrossRef] [PubMed]

27. Wu, X.F.; Chen, L.; Chen, J.P.; Su, X.J.; Liu, Y.; Wang, K.Q.; Qin, W.S.; Qi, H.; Deng, M. The Effect of 60Co $\gamma$-Irradiation on the Structure and Thermostability of Alkaline Lignin and Its Irradiation Derived Degradation Products. Waste Biomass Valorization 2018, 10, 3025-3035. [CrossRef]

28. Vârban, R.; Crișan, I.; Vârban, D.; Ona, A.; Olar, L.; Stoie, A.; Stefan, R. Comparative FT-IR Prospecting for Cellulose in Stems of Some Fiber Plants: Flax, Velvet Leaf, Hemp and Jute. Appl. Sci. 2021, 11, 8570. [CrossRef]

29. Siró, I.; Plackett, D. Microfibrillated cellulose and new nanocomposite materials: A review. Cellulose 2010, 17, 459-494. [CrossRef]

30. Sankhla, S.; Sardar, H.H.; Neogi, S. Greener extraction of highly crystalline and thermally stable cellulose micro-fibers from sugarcane bagasse for cellulose nano-fibrils preparation. Carbohydr. Polym. 2021, 251, 117030. [CrossRef]

31. Domínguez, E.; del Río, P.G.; Romaní, A.; Garrote, G.; Gullón, P.; de Vega, A. Formosolv Pretreatment to Fractionate Paulownia Wood Following a Biorefinery Approach: Isolation and Characterization of the Lignin Fraction. Agronomy 2020, $10,1205$. [CrossRef] 
32. Wu, X.F.; Chen, L.; He, W.Q.; Qi, H.; Zhang, Y.; Zhou, Y.J.; Su, X.J.; Deng, M.; Wang, K.Q. Characterize the physicochemical structure and enzymatic efficiency of agricultural residues exposed to $\gamma$-irradiation pretreatment. Ind. Crop. Prod. 2020, 150, 112228. [CrossRef]

33. Fortunati, E.; Benincasa, P.; Balestra, G.M.; Luzi, F.; Mazzaglia, A.; Del Buono, D.; Puglia, D.; Torre, L. Revalorization of barley straw and husk as precursors for cellulose nanocrystals extraction and their effect on PVA_CH nanocomposites. Ind. Crop. Prod. 2016, 92, 201-217. [CrossRef]

34. Vazquez, M.J.; Garrote, G.; Alonso, J.L.; Dominguez, H.; Parajo, J.C. Refining of autohydrolysis liquors for manufacturing xylooligosaccharides: Evaluation of operational strategies. Bioresour. Technol. 2005, 96, 889-896. [CrossRef]

35. Zdarta, J.; Thygesen, A.; Holm, M.S.; Meyer, A.S.; Pinelo, M. Direct separation of acetate and furfural from xylose by nanofiltration of birch pretreated liquor: Effect of process conditions and separation mechanism. Sep. Purif. Technol. 2020, 239, 116546. [CrossRef]

36. Chen, K.F.; Luo, G.; Lei, Z.F.; Zhang, Z.Y.; Zhang, S.C.; Chen, J.M. Chromatographic separation of glucose, xylose and arabinose from lignocellulosic hydrolysates using cation exchange resin. Sep. Purif. Technol. 2018, 195, 288-294. [CrossRef] 